Article

\title{
Extraction Complex Properties of the Nonlinear Modified Alpha Equation
}

\author{
Haci Mehmet Baskonus ${ }^{1, *(\mathbb{D})}$ and Muzaffer Ercan ${ }^{2}$ \\ 1 Department of Mathematics and Science Education, Faculty of Education, Harran University, \\ Sanliurfa 63510, Turkey \\ 2 Faculty of Arts and Sciences, Harran University, Sanliurfa 63510, Turkey; muzafferercan6347@gmail.com \\ * Correspondence: hmbaskonus@gmail.com
}

Citation: Baskonus, H.M.; Ercan, M. Extraction Complex Properties of the Nonlinear Modified Alpha Equation. Fractal Fract. 2021, 5, 6. https:// doi.org10.3390/fractalfract5010006

Received: 13 November 2020 Accepted: 31 December 2020 Published: 7 January 2021

Publisher's Note: MDPI stays neutral with regard to jurisdictional clai$\mathrm{ms}$ in published maps and institutional affiliations.

Copyright: (C) 2021 by the authors. Licensee MDPI, Basel, Switzerland. This article is an open access article distributed under the terms and conditions of the Creative Commons Attribution (CC BY) license (https:// creativecommons.org/licenses/by/ $4.0 /)$.
Abstract: This paper applies one of the special cases of auxiliary method, which is named as the Bernoulli sub-equation function method, to the nonlinear modified alpha equation. The characteristic properties of these solutions, such as complex and soliton solutions, are extracted. Moreover, the strain conditions of solutions are also reported in detail. Observing the figures plotted by considering various values of parameters of these solutions confirms the effectiveness of the approximation method used for the governing model.

Keywords: modified alpha equation; Bernoulli sub-equation function method; rational function solution; complex solution; contour surface

\section{Introduction}

In the last three decades, we have seen an enthralling research topic on the real world problems expressed by using mathematical models. Qi et al. have investigated some important models used to describe the certain waves in physics [1,2]. In this sense, an interesting model for investigating numerically the nonlinear weakly singular models has been presented by Ray et al. [3]. Syam has worked on the Bernoulli sub-equation method [4]. He has also obtained a lot of different interesting results for the governing model. A few years ago, Mendo has studied the series of wave forces connected with Bernoulli structures [5]. He has also produced a different Bernoulli variable algorithm. Rani et al. have studied on a special matrix that could be solved by Bernoulli polynomials [6]. Jeon et al. have investigated the generalized hypergeometric differential [7]. In 2019, Arqub et al. have studied the Riccati and Bernoulli properties to find new and different solutions for the governing model [8]. Ordokhani et al. have observed some important properties the Bernoulli wavelets with their special cases [9]. Yang has proved a new form of high order Bernoulli polynomials in 2008 [10], which obtained many new special cases about the Bernoulli model. In 2016, Dilcher has searched for identities of the Bernoulli polynomial properties in a physical aspect [11,12]. Furthermore, they have given more detailed information regarding these special functions. Ordokhani et al. have defined an original rational relation based on the Bernoulli wavelet [13]. Tian et al. have worked on the solution of beam problem by using an ansatz method based on the Bernoulli polinomials [14], and so on [15-27].

More general properties of auxiliary and sub-equation function methods have been comprehensively introduced in the literature $[28,29]$. Moreover, there are many published methods for solving similar equations using different techniques and methods [30-49].

In the organization of this paper, in Section 2, we give some preliminaries about the method. In Section 3, we discuss the application of projected method to the nonlinear modified alpha equation (MAE) defined as [21]

$$
u_{t}-u_{x x t}+(\alpha+1) u^{2} u_{x}-\alpha u_{x} u_{x x}-u u_{x x x}=0,
$$


in which $\alpha$ is real constant and non-zero. Islam et al., have applied the modified simple equation method to Equation (1) for getting some important properties [21]. Wazwaz investigated the physical meaning of Equation (1) in a previous study [22].

Comparison and discussion related to the solutions obtained in this paper are presented in Section 4. After the graphical simulations, a conclusion completes the paper.

\section{Fundamental Facts of BSEFM}

This section presents the general properties of BSEFM [23] based on the four steps defined as follows:

Step 1. We consider the following nonlinear partial differential equation (NLPDE) given as

$$
P\left(u, u_{x}, u_{x t}, u_{x x}, u^{2}, \ldots\right)=0,
$$

which is taking into account the travelling wave transformation

$$
u(x, t)=U(\eta), \eta=k x-c t,
$$

where $k \neq 0, c \neq 0$. Substituting Equation (3) into Equation (2) yields the following ordinary differential equation:

$$
\begin{gathered}
N\left(U, U^{\prime}, U^{\prime \prime}, U^{2}, \ldots\right)=0, \\
\text { where } U=U(\eta), U^{\prime}=\frac{d U}{d \eta}, U^{\prime \prime}=\frac{d^{2} U}{d \eta^{2}}, \ldots
\end{gathered}
$$

Step 2. In this step, we take the following trial solution equation to the Equation (4):

$$
U(\eta)=\sum_{i=0}^{n} a_{i} F^{i}=a_{0}+a_{1} F+a_{2} F^{2}+\ldots+a_{n} F^{n},
$$

and

$$
F^{\prime}=b F+d F^{M}, b \neq 0, d \neq 0, M \in R-\{0,1,2\},
$$

where $F(\eta)$ is Bernoulli differential polynomial. Substituting Equation (5) along with Equation (6) into Equation (4), it produces an algebraic equation of polynomial $\Omega(F)$ as follows:

$$
\Omega(F)=\rho_{s} F^{s}+\ldots+\rho_{1} F+\rho_{0}=0 .
$$

We can find more than one solution by obtaining a relation between $M$ and $n$ via the balancing principle and then using this relation.

Step 3. If we take into account that all the coefficients of $\Omega(F)$ are zero:

$$
\rho_{i}=0, i=0, \ldots, s .
$$

If we solve this system, we will find and control the values of

$$
a_{0}, a_{1}, a_{2}, \ldots, a_{n}
$$

Step 4. Solving Equation (6), we find the following according to $b$ and $d$ :

$$
\begin{gathered}
F(\eta)=\left[\frac{-d}{b}+\frac{\varepsilon}{e^{b(M-1) \eta}}\right]^{\frac{1}{1-M}}, b \neq d, \\
F(\eta)=\left[\frac{(\varepsilon-1)+(\varepsilon+1) \tanh \left(\frac{b(1-M) \eta}{2}\right)}{1-\tanh \left(\frac{b(1-M) \eta}{2}\right)}\right]^{\frac{1}{1-M}}, b=d, \quad \varepsilon \in R .
\end{gathered}
$$


Using a complete discrimination system for polynomial parameters, we find the solutions to Equation (4), using some computational programs, and organize the exact solutions to Equation (4). In order to better understand the results obtained in this way, we can draw the two and three dimensional surfaces of the solutions by considering the appropriate parameter values.

\section{Implementation of the BSEFM}

This section of the manuscript applies the BSEFM to the MAE to obtain new complex and exponential solutions. Using

$$
u(x, t)=U(\eta), \eta=k x-c t
$$

where $c, k$ are real constants and non-zero, we obtain the nonlinear ordinary equation as follows:

$$
6 c k^{2} U^{\prime \prime}-6 k^{3} U U^{\prime \prime}+3 k^{3}(1-\alpha)\left(U^{\prime}\right)^{2}-6 c U+2 k(\alpha+1) U^{3}=0 .
$$

With the help of the balance principle, it is obtained a relationship between $n$ and $M$ as follows:

$$
2 M=n+2 .
$$

This gives some new analytical solutions for the governing model being Equation (1).

Case 1: Considering as $n=4$ and $M=3$ produce the following trial solution for Equation (10):

$$
\begin{gathered}
U=a_{0}+a_{1} F+a_{2} F^{2}+a_{3} F^{3}+a_{4} F^{4}, \\
U^{\prime}=a_{1} b F+a_{1} d F^{3}+2 a_{2} b F^{2}+2 a_{2} d F^{4}+3 a_{3} b F^{3}+3 a_{3} d F^{5}+4 a_{4} b F^{4}+4 a_{4} d F^{6},
\end{gathered}
$$

and

$$
\begin{gathered}
U^{\prime \prime}=a_{1} d^{2} F+4 a_{1} b d F^{3}+3 a_{1} b^{2} F^{5}+4 a_{2} d^{2} F^{2}+12 a_{2} b d F^{4}+8 a_{2} b^{2} F^{6}+9 a_{3} d^{2} F^{3} \\
+24 a_{3} b d F^{5}+15 a_{3} b^{2} F^{7}+16 a_{4} d^{2} F^{4}+40 a_{4} b d F^{6}+24 a_{4} b^{2} F^{8} .
\end{gathered}
$$

where $a_{4} \neq 0, b \neq 0, d \neq 0$. Putting Equations (12)-(14) into Equation (10), it gives a system of algebraic equations of $F$. With the help of powerful computational programs, we get the following coefficients and solutions.

Case 1.1. If it is selected follows:

$$
\begin{aligned}
& a_{0}=-\frac{3 d^{2} \alpha+\sqrt{3} \sqrt{-d^{4}\left(-4+\alpha^{2}\right)}}{2 d^{2}(1+\alpha)}, a_{1}=a_{3}=0, \\
& k=-\frac{1}{2} \sqrt{-\frac{d^{2}(2+a)(-1+2 \alpha)+\sqrt{3} \sqrt{-d^{4}\left(-4+\alpha^{2}\right)}}{d^{4}(1+\alpha)(2+\alpha)}}, \\
& a_{2}=-\frac{6 b}{d^{3}(1+\alpha)^{2}}\left(d^{2}(2+a)(-1+2 \alpha)+\sqrt{3} \sqrt{-d^{4}\left(-4+\alpha^{2}\right)}\right), \\
& a_{4}=-\frac{6 b^{2}}{d^{4}(1+\alpha)^{2}}\left(d^{2}(2+a)(-1+2 \alpha)+\sqrt{3} \sqrt{-d^{4}\left(-4+\alpha^{2}\right)}\right), \\
& c=-\frac{1}{4 d^{2}(1+\alpha)} \sqrt{-\frac{d^{2}(2+a)(-1+2 \alpha)+\sqrt{3} \sqrt{-d^{4}\left(-4+\alpha^{2}\right)}}{d^{4}(1+\alpha)(2+\alpha)}} \\
& \quad \times\left(\alpha \sqrt{3} \sqrt{-d^{4}\left(-4+\alpha^{2}\right)}+d^{2}\left(2+\alpha^{2}\right)\right),
\end{aligned}
$$

we find the following new singular soliton solution for the governing model being Equation (1):

$$
u_{1}(x, t)=\sigma-\frac{\omega}{d^{4}(1+\alpha)^{2}\left(-\frac{b}{d}+e^{-2 d\left(-\frac{1}{2} x \tau+t \tau \omega\right)} \varepsilon\right)^{2}}-\frac{\omega}{b d^{3}(1+\alpha)^{2}\left(-\frac{b}{d}+e^{-2 d\left(-\frac{1}{2} x \tau+t \tau \omega\right)} \varepsilon\right)}
$$


in which

$$
\begin{gathered}
\tau=\sqrt{-\frac{d^{2}(2+\alpha)(-1+2 \alpha)+\sqrt{3} \sqrt{-d^{4}\left(-4+\alpha^{2}\right)}}{d^{4}(1+\alpha)(2+\alpha)}}, \omega=6 b^{2}\left(d^{2}(2+\alpha)(-1+2 \alpha)+\sqrt{3} \sqrt{-d^{4}\left(-4+\alpha^{2}\right)}\right), \\
\omega=\frac{\left(\sqrt{3} \alpha \sqrt{-d^{4}\left(-4+\alpha^{2}\right)}+d^{2}\left(2+\alpha^{2}\right)\right)}{4 d^{2}(1+\alpha)}, \sigma=-\frac{3 d^{2} \alpha+\sqrt{3} \sqrt{-d^{4}\left(-4+\alpha^{2}\right)}}{2 d^{2}(1+\alpha)},-2<\alpha<-1
\end{gathered}
$$

for validity of Equation (16). Choosing the suitable values of parameters in Equation (16), we plot various figures as follows as being in Figures 1 and 2.
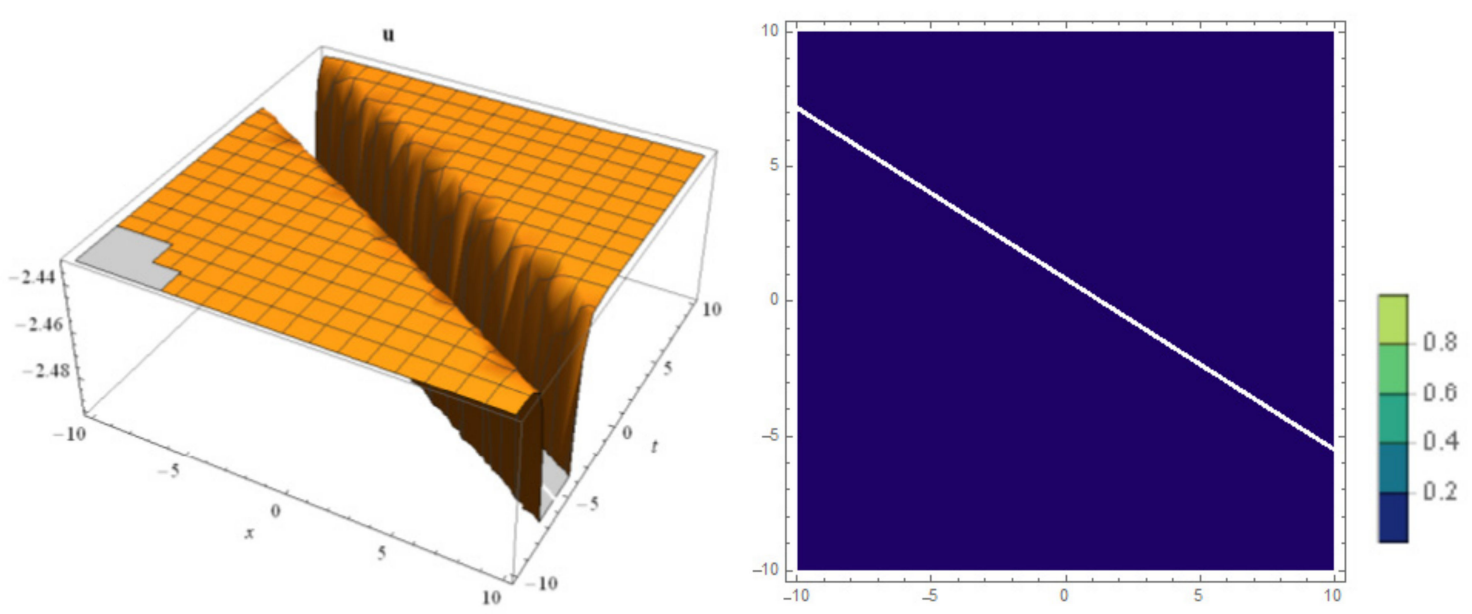

Figure 1. The 3D and contour surfaces of Equation (16) under the values of $d=0.1, \alpha=-1.8, b=0.5, \varepsilon=0.4$.

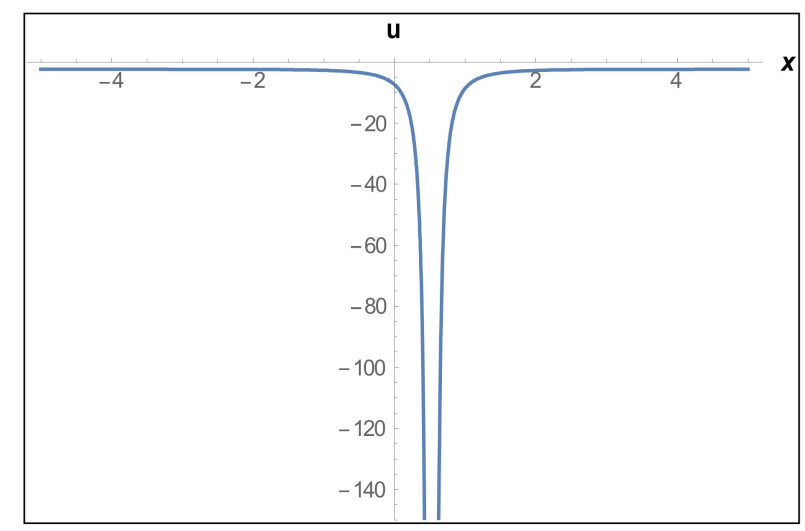

Figure 2. The 2D graph of Equation (16) under the values of $d=0.1, \alpha=-1.8, b=0.5, \varepsilon=0.4$, $t=0.5,-5<x<5$.

Case 1.2. For $b \neq d$, when they are considered as follows:

$$
a_{0}=a_{1}=a_{3}=0, a_{2}=\frac{-24 b c}{1+\alpha}, a_{4}=\frac{96 b^{2} c^{2}}{2+3 a+\alpha^{2}}, k=\frac{2 c}{2+\alpha}, d=-\frac{2+\alpha}{4 c},
$$

This produces a new singular soliton solution for the governing model as:

$$
u_{2}(x, t)=-\frac{24 b c}{1+a}\left(\frac{4 b c}{2+a}+\varepsilon e^{\frac{2+a}{2 c}\left(-c t+\frac{2 c}{2+a} x\right)}\right)^{-1}+\frac{96 b^{2} c^{2}}{\alpha^{2}+3 a+2}\left(\frac{4 b c}{2+a}+\varepsilon e^{\frac{2+a}{2 c}\left(-c t+\frac{2 c}{2+a} x\right)}\right)^{-2} .
$$

The strain condition is also given as $\alpha \neq-1, \alpha \neq-2$. We can observe the wave surfaces of Equation (18) as being in Figures 3 and 4. 

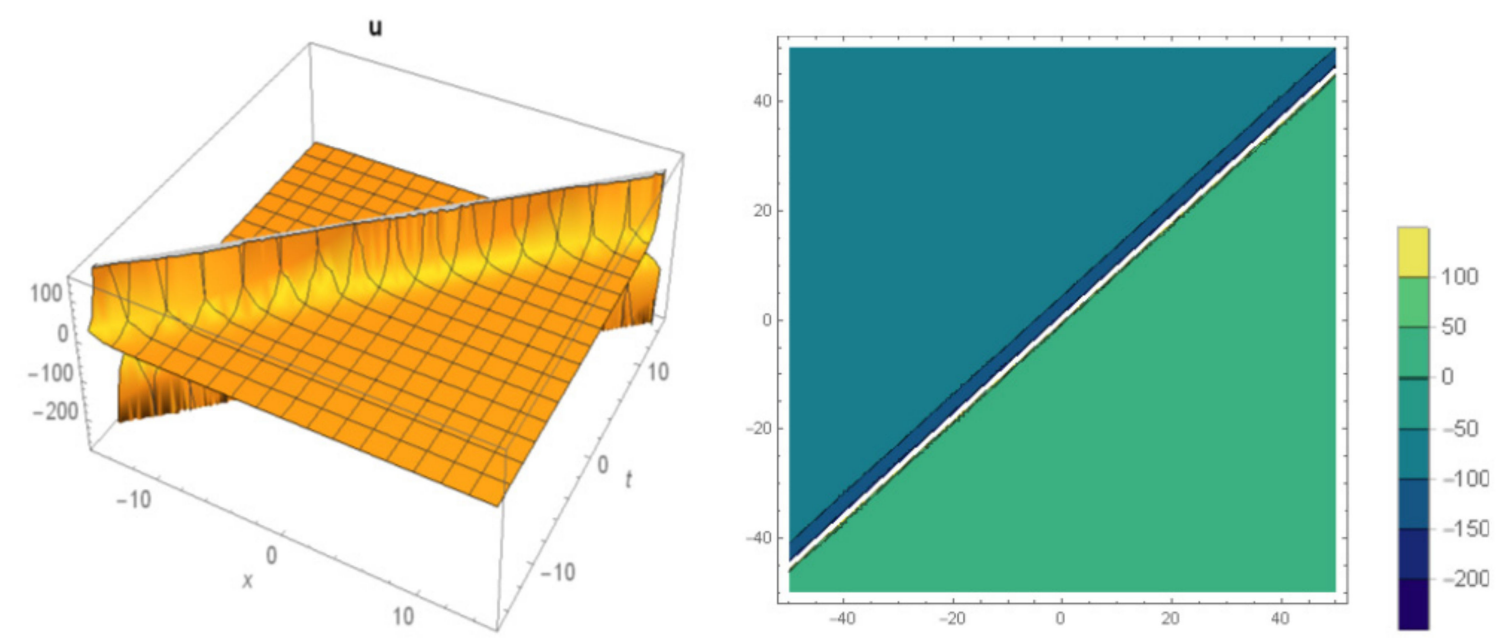

Figure 3. 3D and contour graphs of Equation (18) for $\alpha=0.2, b=0.3, c=-0.5, \varepsilon=0.4, d=0.1,-15<x<15,-15<t<15$.

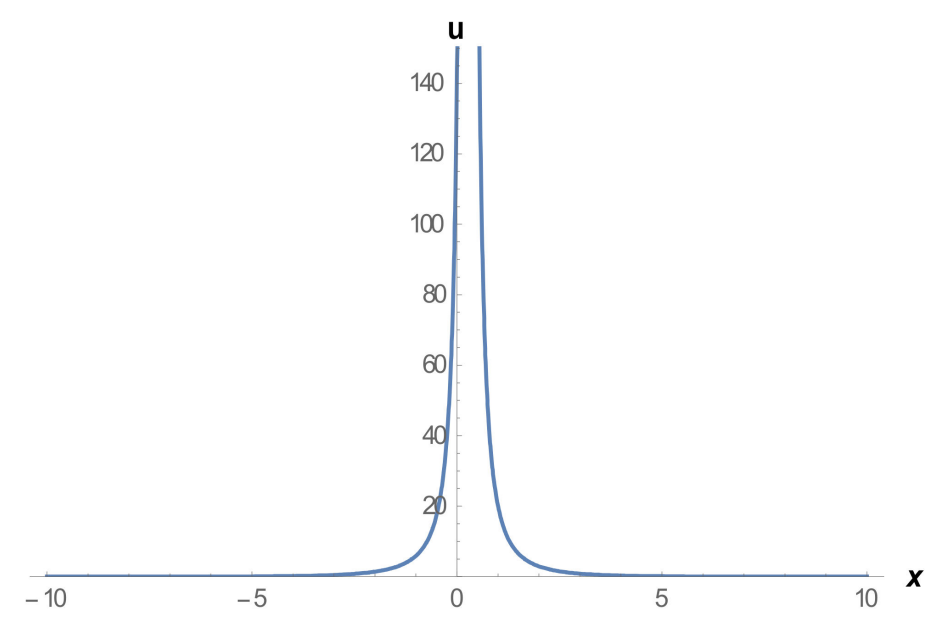

Figure 4. 2D graph of Equation (18) for $\alpha=0.2, b=0.3, c=-0.5, \varepsilon=0.4, d=0.1, t=0.6$, $-10<x<10$.

Case 1.3. If we select the following complex coefficient together with $b \neq d$,

$$
\begin{aligned}
& a_{4}=4, k=1, a_{0}=i, a_{1}=a_{3}=0, a_{2}=4 \sqrt{-1+3 i}, b=-\frac{1}{10} \sqrt{11-2 i}, c=\frac{-7}{13}+\frac{4 i}{13}, \\
& d=-\frac{1}{2} \sqrt{\frac{-1}{5}+\frac{7 i}{5}}, \alpha=\frac{8}{13}-\frac{12 i}{13}
\end{aligned}
$$

it produces a complex soliton solution for the governing model as:

$$
\begin{gathered}
u_{3}(x, t)=i+4\left(-\frac{1}{\sqrt{-1+7 i}} \sqrt{\frac{11}{5}-\frac{2 i}{5}}+\varepsilon e^{\sqrt{\frac{-1}{5}+\frac{7 i}{5}}\left(x+\left(\frac{7}{13}-\frac{4 i}{13}\right) t\right)}\right)^{-2} \\
+4 \sqrt{-1+3 i}\left(-\frac{1}{\sqrt{-1+7 i}} \sqrt{\frac{11}{5}-\frac{2 i}{5}}+\varepsilon e^{\sqrt{\frac{-1}{5}+\frac{7 i}{5}}\left(x+\left(\frac{7}{13}-\frac{4 i}{13}\right) t\right)}\right)^{-1} .
\end{gathered}
$$

Wave surfaces of Equation (20) can be observed in Figures 5-7. 

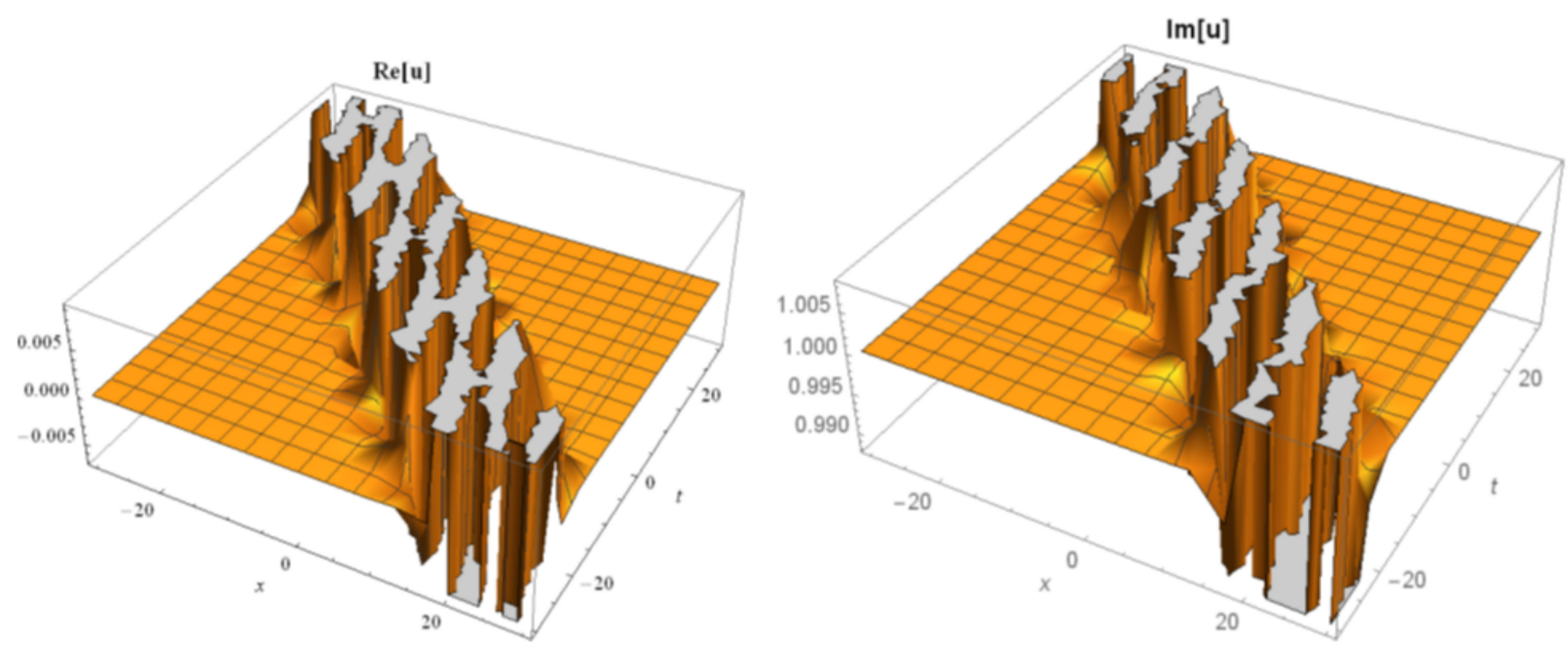

Figure 5. The 3D surfaces of Equation (20) under the values of $\varepsilon=0.4,-30<x<30,-30<t<30$.
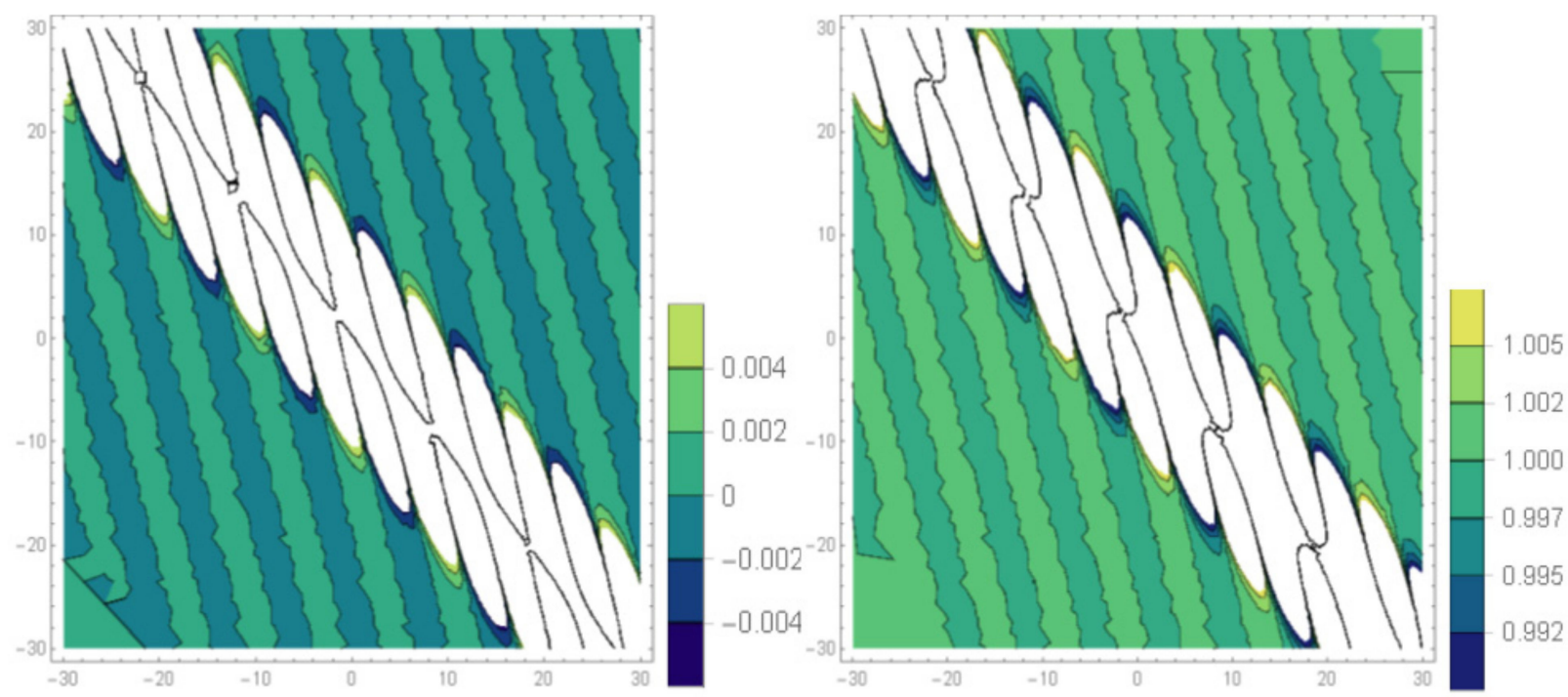

Figure 6. The contour surfaces of Equation (20) under the values of $\varepsilon=0.4,-30<x<30,-30<t<30$.
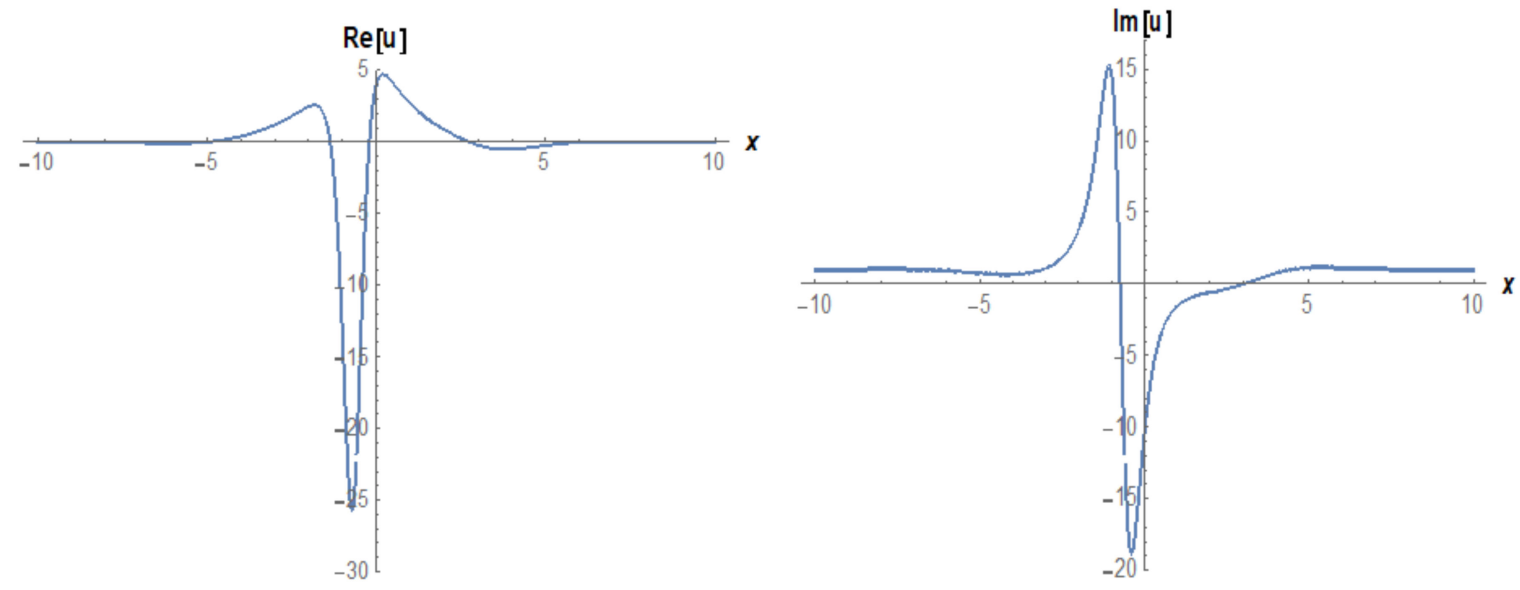

Figure 7. The 2D surfaces of Equation (20) under the values of $\varepsilon=0.4, t=0.5,-10<x<10$. 
Case 1.4. When choosing the following other complex coefficients and also $b \neq d$,

$$
\begin{aligned}
& a_{4}=4, k=1, a_{0}=i, a_{1}=a_{3}=0, a_{2}=-4 \sqrt{-1+3 i}, b=-\frac{1}{10} \sqrt{11-2 i}, \\
& d=\frac{1}{2} \sqrt{\frac{-1}{5}+\frac{7 i}{5}}, \alpha=\frac{8}{13}-\frac{12 i}{13}, c=\frac{-7}{13}+\frac{4 i}{13}
\end{aligned}
$$

it produces another complex soliton solution to the governing model as:

$$
\begin{gathered}
u_{4}(x, t)=i+4\left(\frac{1}{\sqrt{-1+7 i}} \sqrt{\frac{11}{5}-\frac{2 i}{5}}+\varepsilon e^{-\sqrt{\frac{-1}{5}+\frac{7 i}{5}}\left(x+\left(\frac{7}{13}-\frac{4 i}{13}\right) t\right)}\right)^{-2} \\
-4 \sqrt{-1+3 i}\left(\frac{1}{\sqrt{-1+7 i}} \sqrt{\frac{11}{5}-\frac{2 i}{5}}+\varepsilon e^{-\sqrt{\frac{-1}{5}+\frac{7 i}{5}}\left(x+\left(\frac{7}{13}-\frac{4 i}{13}\right) t\right)}\right)^{-1} .
\end{gathered}
$$

Under the suitable choosing of the values of these parameters, we plot various graphs as being Figures 8-10.
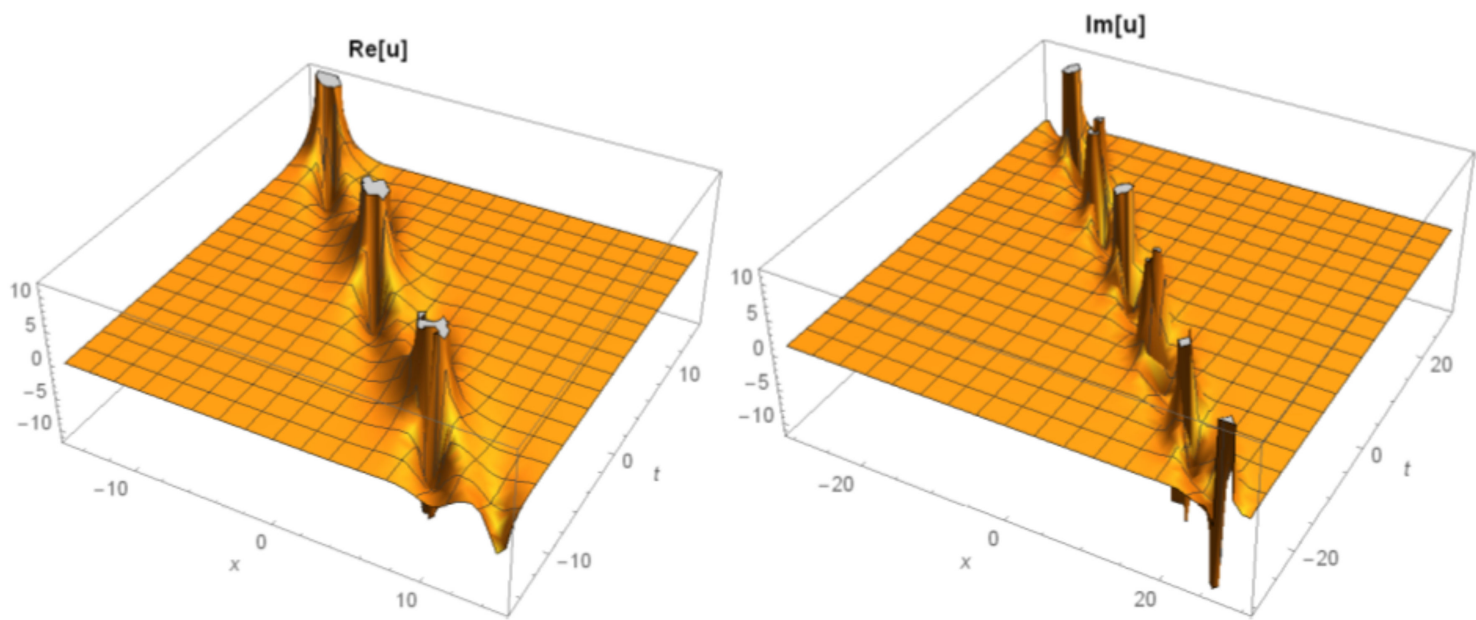

Figure 8. The 3D surfaces of Equation (22) under the values of $\varepsilon=0.4,-15<x<15,-15<t<15$.
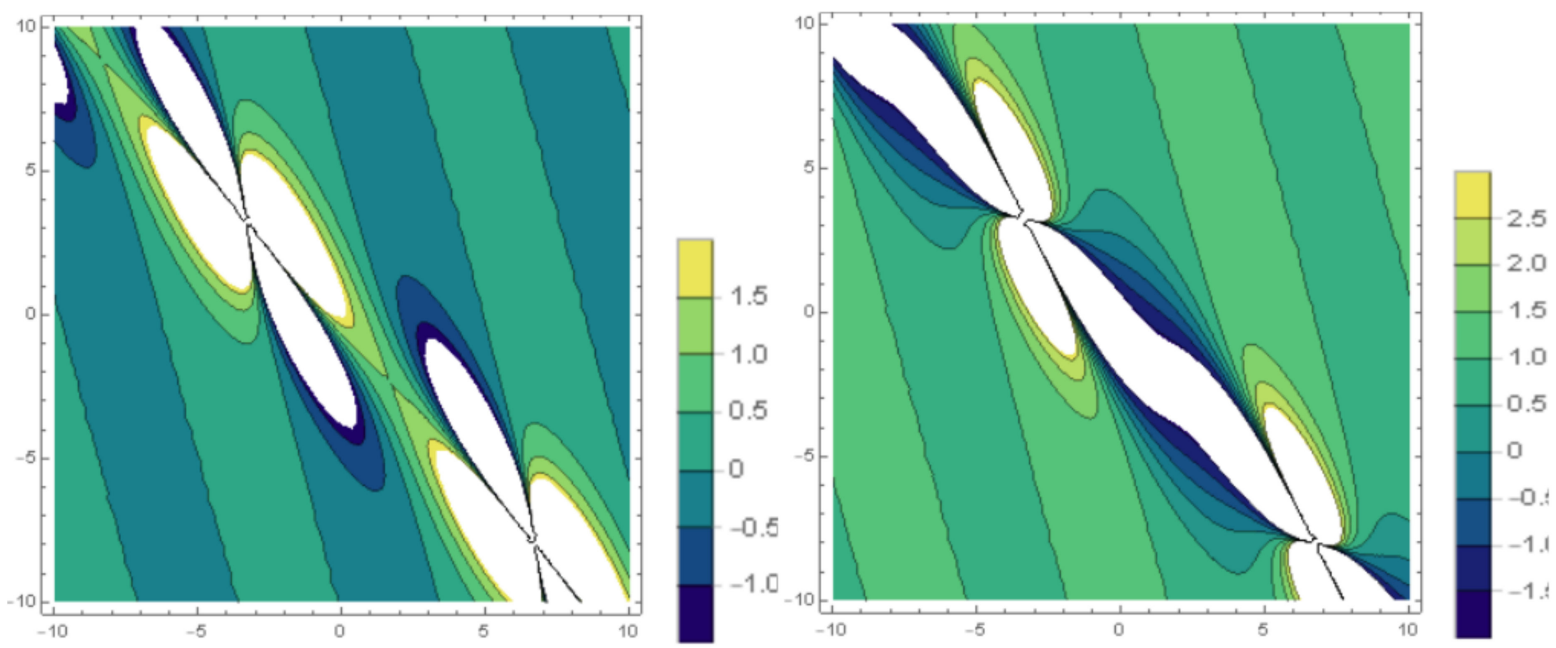

Figure 9. The contour surfaces of Equation (22) under the values of $\varepsilon=0.4,-15<x<15,-15<t<15$. 

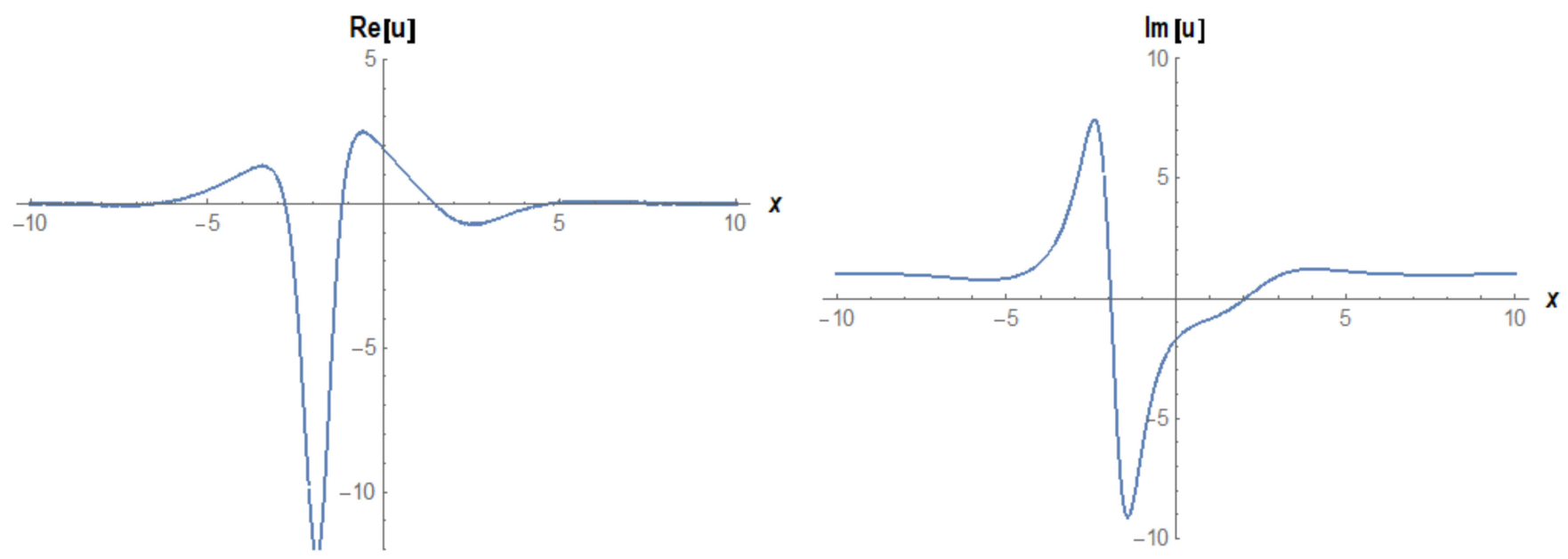

Figure 10. The 2D surfaces of Equation (22) under the values of $\varepsilon=0.4, t=0.5,-15<x<15$.

Case 1.5. Choosing the following other complex coefficients by considering $b \neq d$,

$$
\begin{aligned}
& a_{4}=-i, k=1, a_{0}=2, a_{1}=0, a_{2}=(-2+2 i) \sqrt{5}, a_{3}=0, b=\frac{1}{10}-\frac{i}{10}, d=\frac{-2}{\sqrt{5}} \\
& \alpha=\frac{-1}{13}, c=\frac{16}{13}
\end{aligned}
$$

gives another complex exponential function solution as:

$$
u_{5}(x, t)=2-i\left(\frac{1-i}{4 \sqrt{5}}+\varepsilon e^{\frac{4}{\sqrt{5}}\left(x-\frac{16}{13} t\right)}\right)^{-2}-(2-2 i) \sqrt{5}\left(\frac{1-i}{4 \sqrt{5}}+\varepsilon e^{\frac{4}{\sqrt{5}}\left(x-\frac{16}{13} t\right)}\right)^{-1} .
$$

Choosing the suitable values of these parameters, we present several simulations as Figures 11-13.
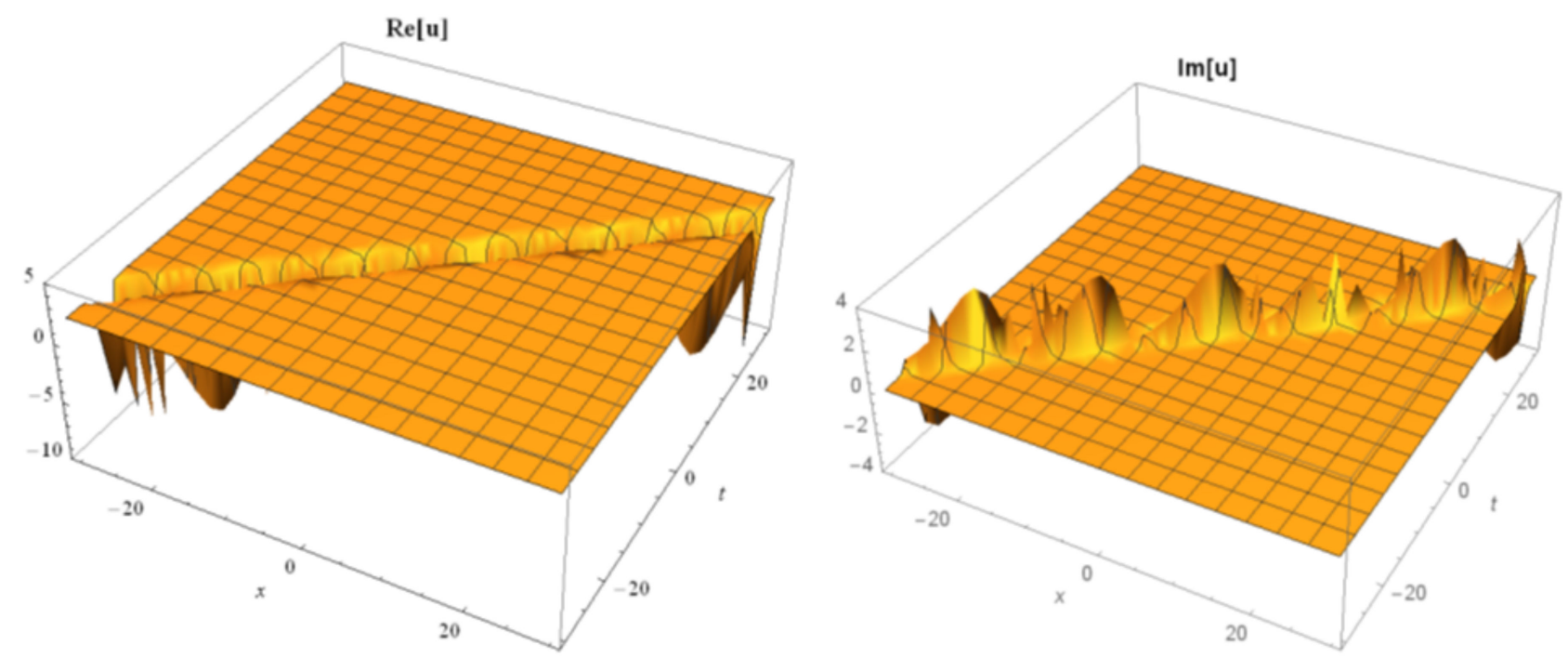

Figure 11. The 3D simulations of Equation (24) under the values of $\varepsilon=0.4,-30<x<30,-30<t<30$. 


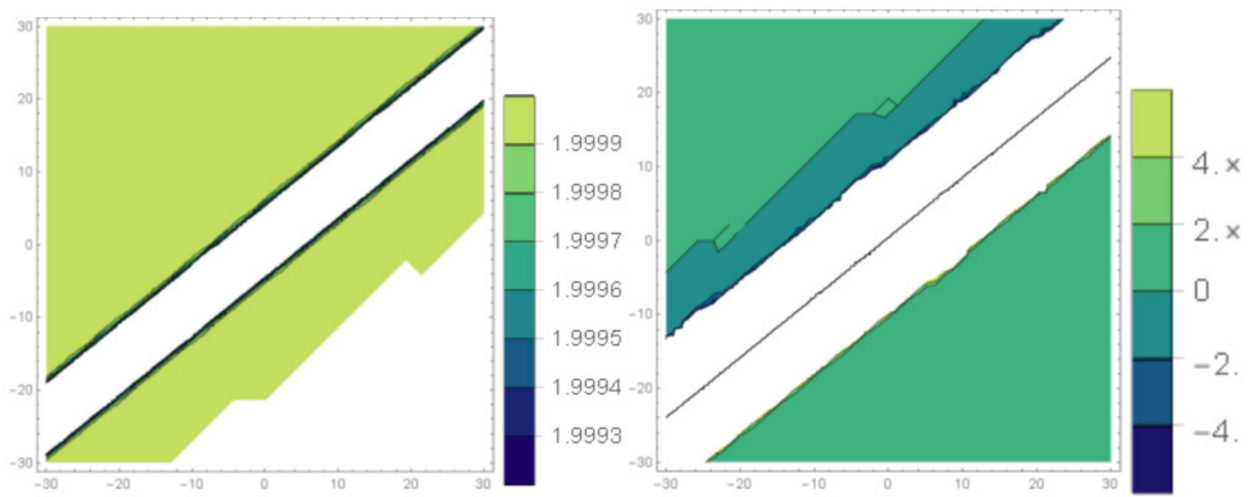

Figure 12. The contour graphs of Equation (24) under the values of $\varepsilon=0.4,-30<x<30,-30<t<30$.
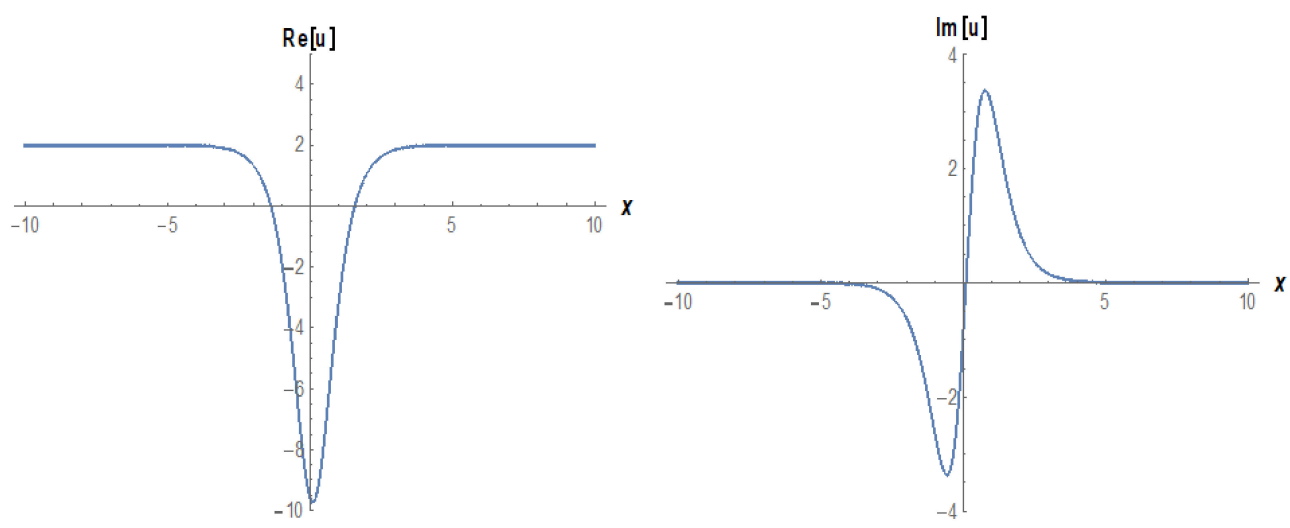

Figure 13. The 2D graphs of Equation (24) under the values of $\varepsilon=0.4, t=0.5,-10<x<10$.

Case 1.6. Taking the following other complex coefficients with $b \neq d$,

$$
\begin{aligned}
& a_{4}=-i, k=1, a_{0}=2, a_{1}=0, a_{2}=(2-2 i) \sqrt{5}, a_{3}=0, b=-\frac{1}{10}+\frac{i}{10}, d=\frac{-2}{\sqrt{5}} \\
& \alpha=\frac{-1}{13}, c=\frac{16}{13}
\end{aligned}
$$

gives another complex exponential function solution as:

$$
u_{6}(x, t)=2-i\left(\frac{-1+i}{4 \sqrt{5}}+\varepsilon e^{\frac{4}{\sqrt{5}}\left(x-\frac{16}{13} t\right)}\right)^{-2}+(2-2 i) \sqrt{5}\left(\frac{-1+i}{4 \sqrt{5}}+\varepsilon e^{\frac{4}{\sqrt{5}}\left(x-\frac{16}{13} t\right)}\right)^{-1} .
$$

Various simulations of Equation (26) may be observed in Figures 14-16.
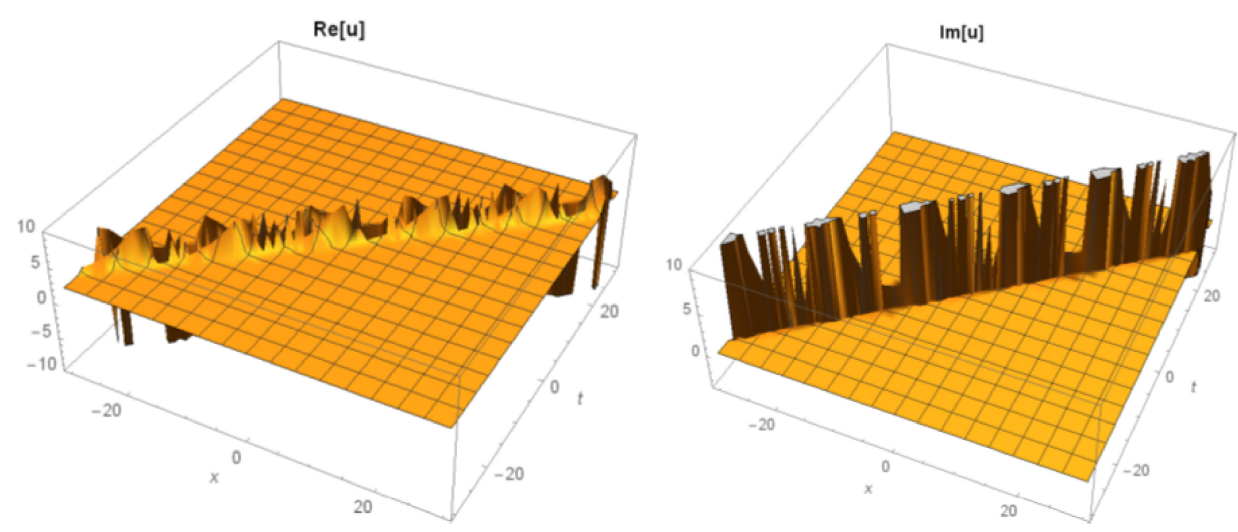

Figure 14. The 3D simulations of Equation (26) under the values of $\varepsilon=0.4,-30<x<30,-30<t<30$. 

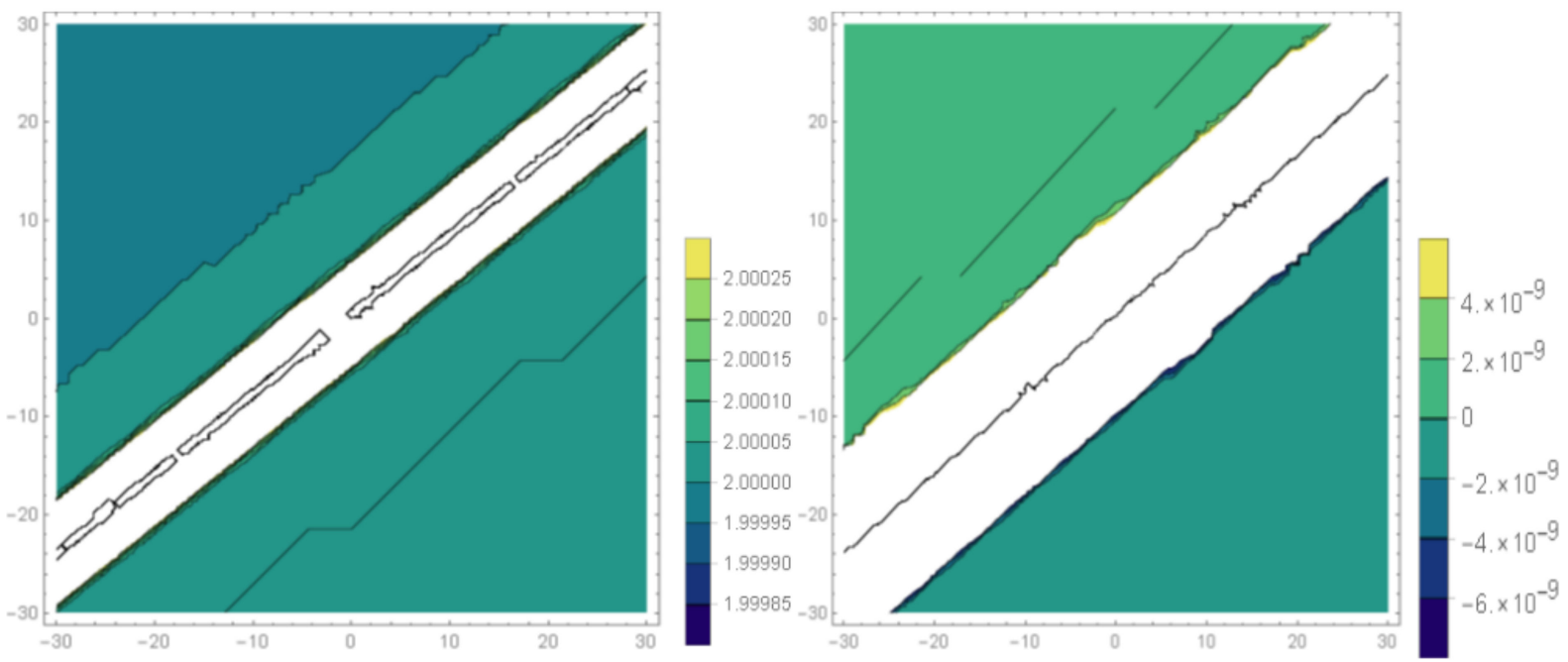

Figure 15. The contour graphs of Equation (26) under the values of $\varepsilon=0.4,-30<x<30,-30<t<30$.
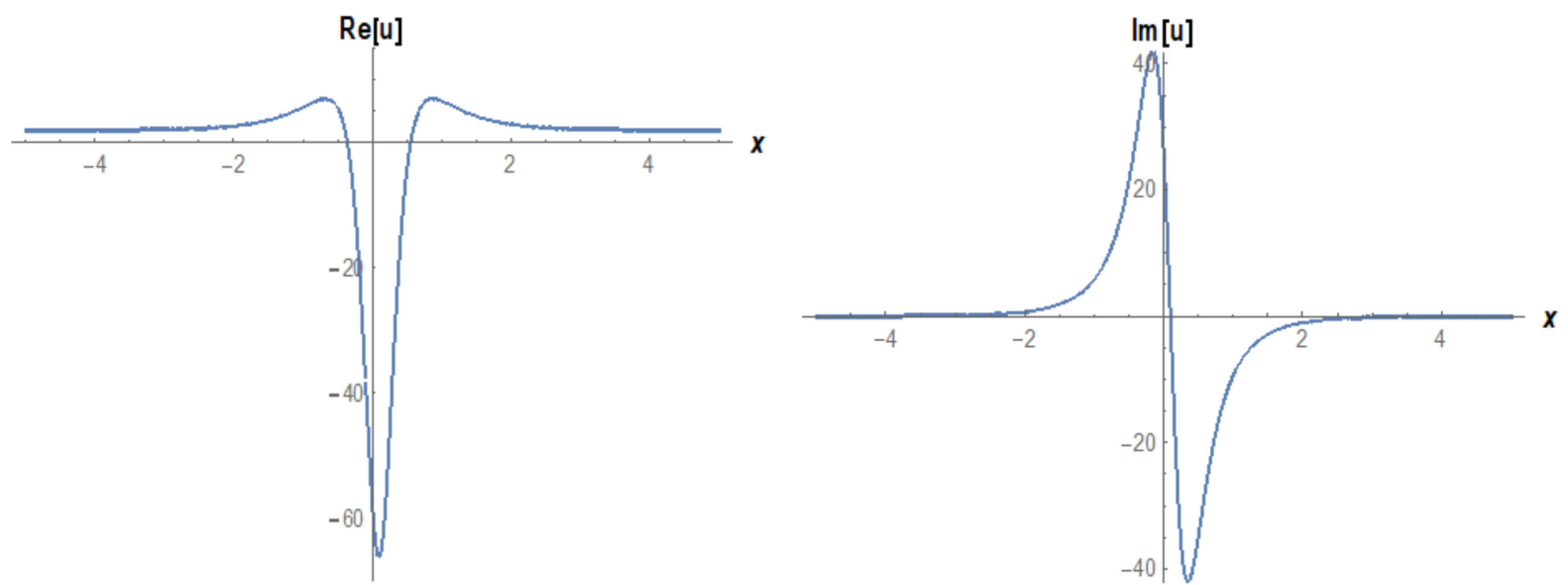

Figure 16. The 2D graphs of Equation (26) under the values of $\varepsilon=0.4, t=0.5,-5<x<5$.

Case 2. Taking $n=6$ and $M=4$, we can write as follows:

$$
U=a_{0}+a_{1} F+a_{2} F^{2}+a_{3} F^{3}+a_{4} F^{4}+a_{5} F^{5}+a_{6} F^{6},
$$

and

$$
\begin{aligned}
& U^{\prime}=a_{1} F^{\prime}+2 a_{2} F F^{\prime}+3 a_{3} F^{2} F^{\prime}+4 a_{4} F^{3} F^{\prime}+5 a_{5} F^{4} F^{\prime}+6 a_{6} F^{5} F^{\prime}, \\
& U^{\prime \prime}=\ldots
\end{aligned}
$$

where $a_{6} \neq 0, b \neq 0, d \neq 0$. Putting Equations (27) and (28) into Equation (10) produces some entirely new analytical solutions for the governing model as follows.

Case 2.1: When

$$
\begin{aligned}
& d=2, a_{0}=a_{1}=a_{2}=a_{4}=a_{5}=0, a_{3}=(-1+i) \sqrt{3 / 5}, a_{6}=i, b=(1-i) \sqrt{5 / 3} \\
& k=1 / 6, \alpha=-11 / 6, c=1 / 72
\end{aligned}
$$

another new complex soliton solution is extracted as:

$$
u_{7}(x, t)=i\left(\frac{i \sqrt{5}-\sqrt{5}}{2 \sqrt{3}}+\varepsilon e^{-x+\frac{t}{12}}\right)^{-2}+(i-1) \frac{\sqrt{3}}{\sqrt{5}}\left(\frac{i \sqrt{5}-\sqrt{5}}{2 \sqrt{3}}+\varepsilon e^{-x+\frac{t}{12}}\right)^{-1}
$$


in which $\varepsilon$ is a real constant with non-zero. Under the suitable chosen of parameters, we can presents various graphs as in Figures 17-19.
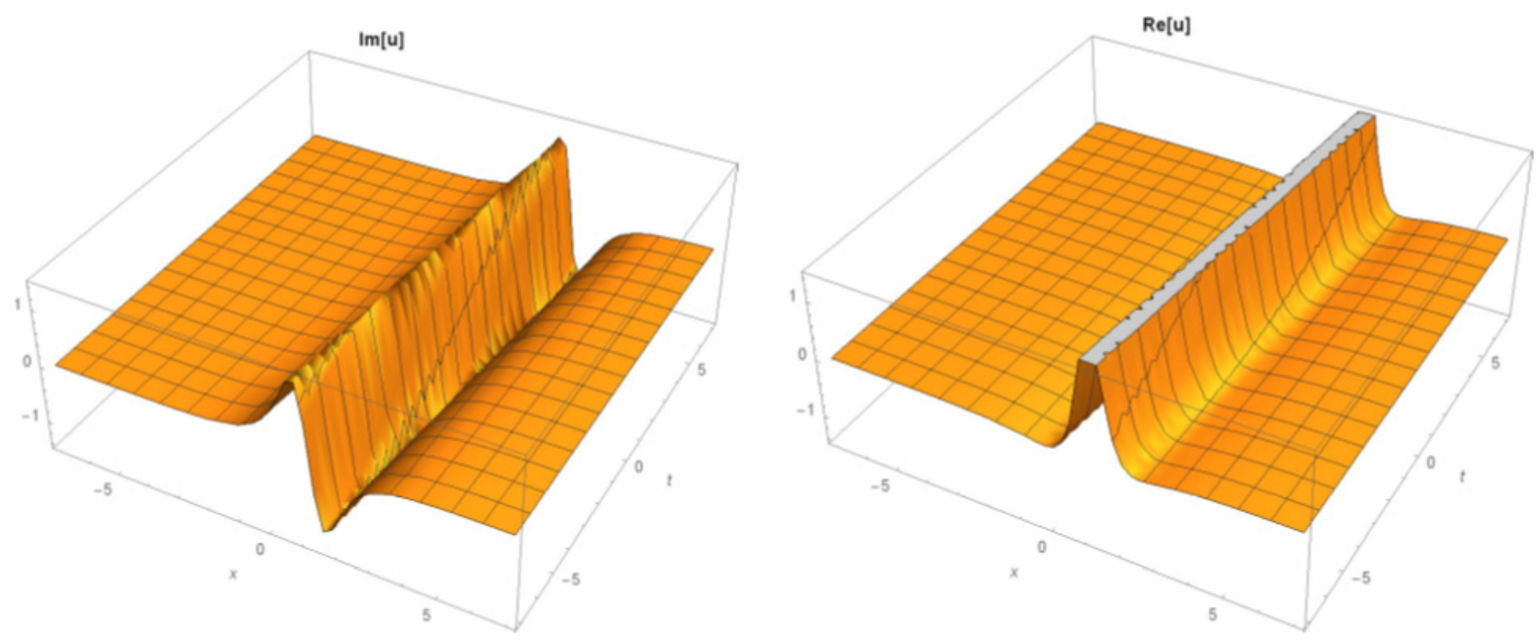

Figure 17. The 3D surfaces of Equation (30) under the values of $\varepsilon=5,-7<x<7,-7<t<7$.

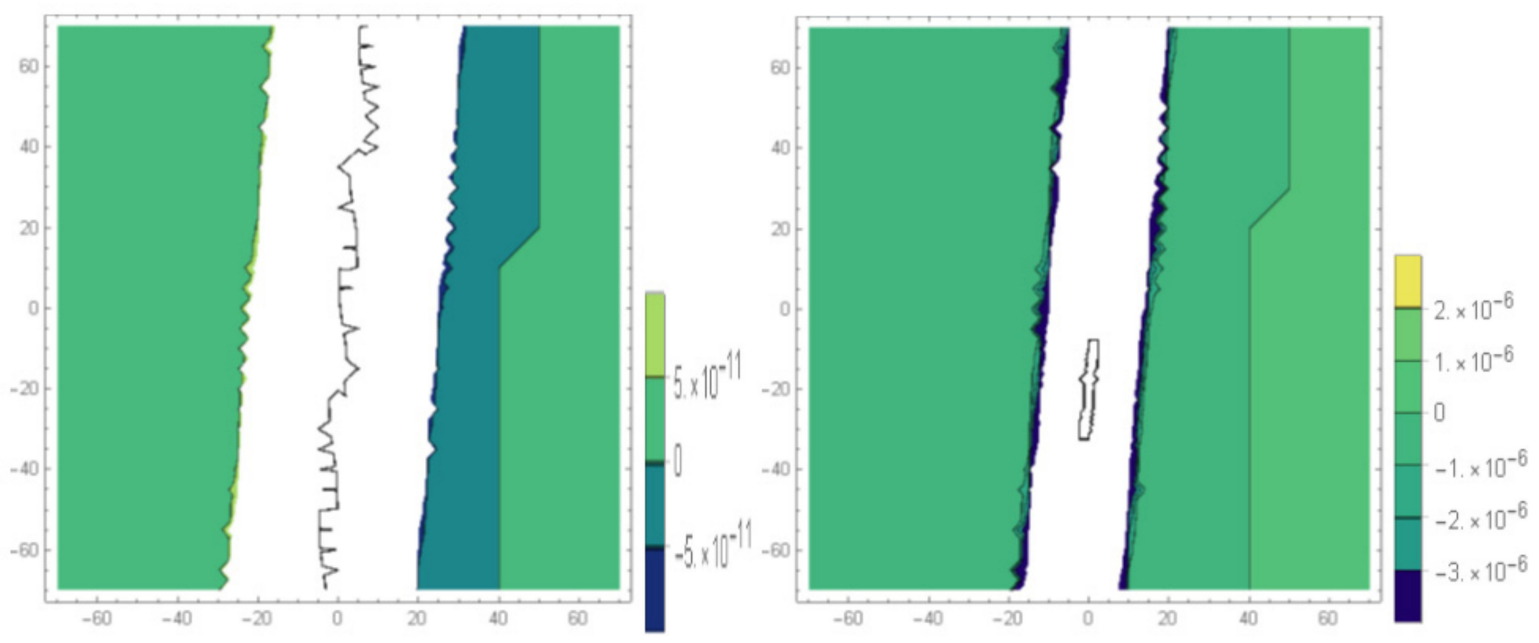

Figure 18. The contour surfaces of Equation (30) under the values of $\varepsilon=5,-70<x<70,-70<t<70$.
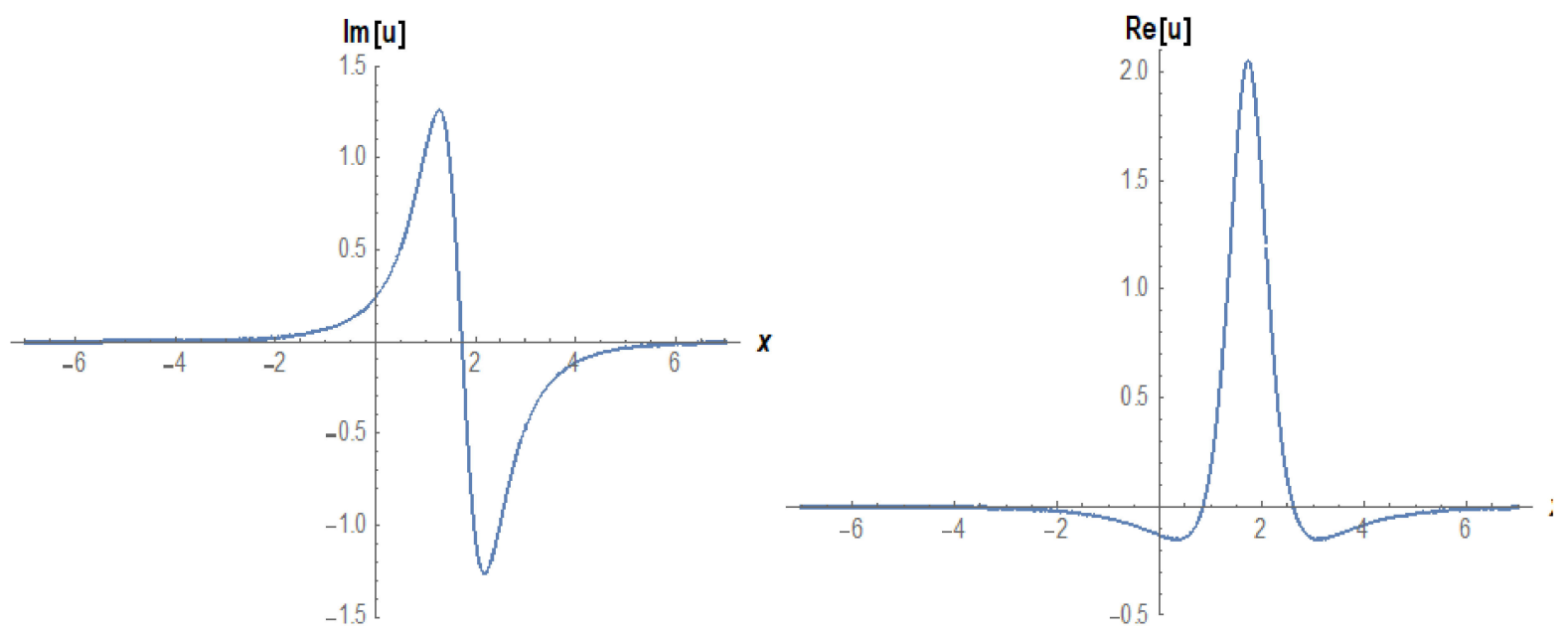

Figure 19. The $2 \mathrm{D}$ surfaces of Equation (30) under the values of $\varepsilon=5, t=0.3,-7<x<7$. 
Case 2.2. Considering the following:

$$
\begin{aligned}
& d=2, a_{0}=a_{1}=a_{2}=a_{4}=a_{5}=0, a_{3}=(\sqrt{6}(1+\alpha) \sqrt{2+\alpha}) /(i(1+\alpha))^{3 / 2}, a_{6}=i, \\
& k=1 / 6, b=(-\sqrt{2 / 3} \sqrt{i(1+\alpha)}) / \sqrt{2+\alpha}, c=(2+\alpha) / 12
\end{aligned}
$$

another new complex mixed dark soliton solution is extracted as:

$$
u_{8}(x, t)=i\left(\frac{1-\operatorname{Tanh}(f(x, t))}{\omega+\varepsilon+(\varepsilon-\omega) \operatorname{Tanh}(f(x, t))}\right)^{2}+\frac{1-\operatorname{Tanh}(f(x, t))}{\omega+\varepsilon+(\varepsilon-\omega) \operatorname{Tanh}(f(x, t))},
$$

in which $\varepsilon, \alpha$ are real constants and non-zero and also

$$
\begin{gathered}
\omega=\frac{\sqrt{i(1+\alpha)}}{\sqrt{12+6 \alpha}}, \sigma=\frac{\sqrt{6}(1+\alpha) \sqrt{2+\alpha}}{(i(1+\alpha))^{3 / 2}} \\
f(x, t)=\frac{2+\alpha}{4} t-\frac{x}{2} .
\end{gathered}
$$

We plot its surfaces in Figures 20-22.
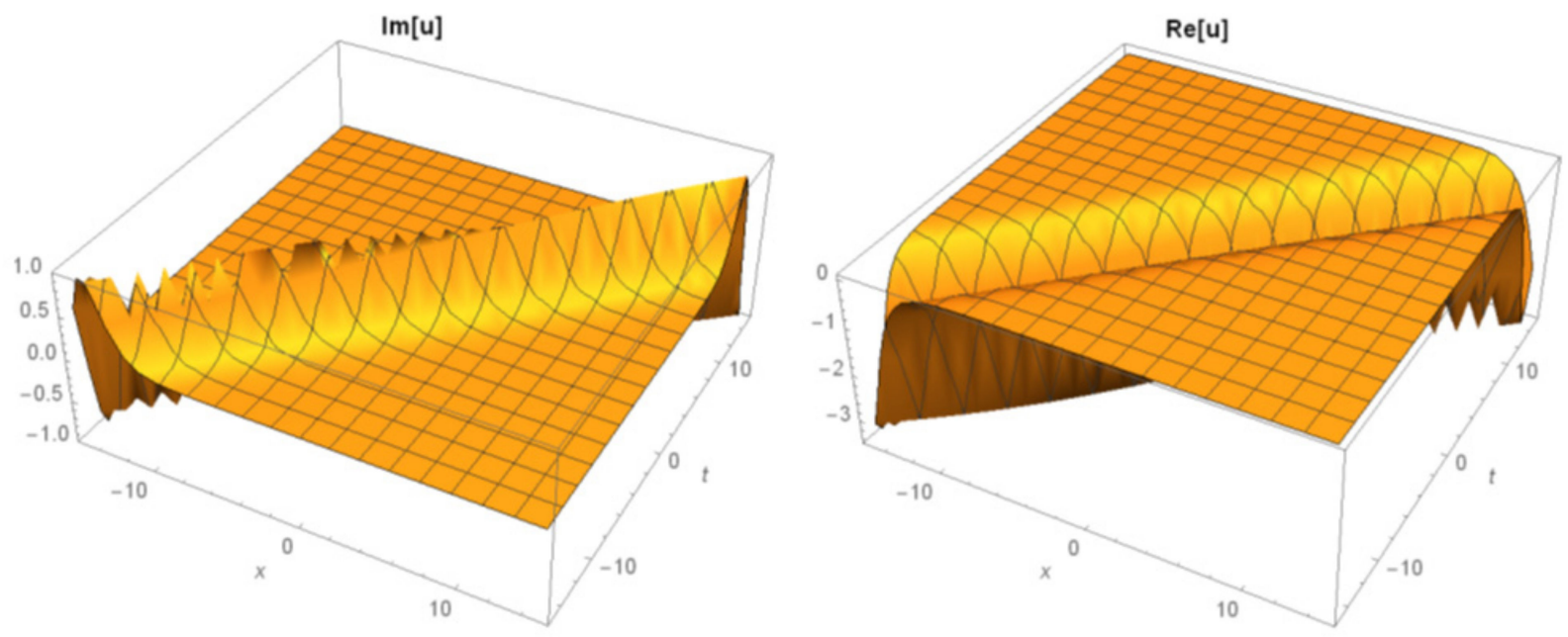

Figure 20. The 3D surfaces of Equation (32) for $\varepsilon=0.4, \alpha=0.1,-15<x<15,-15<t<15$.
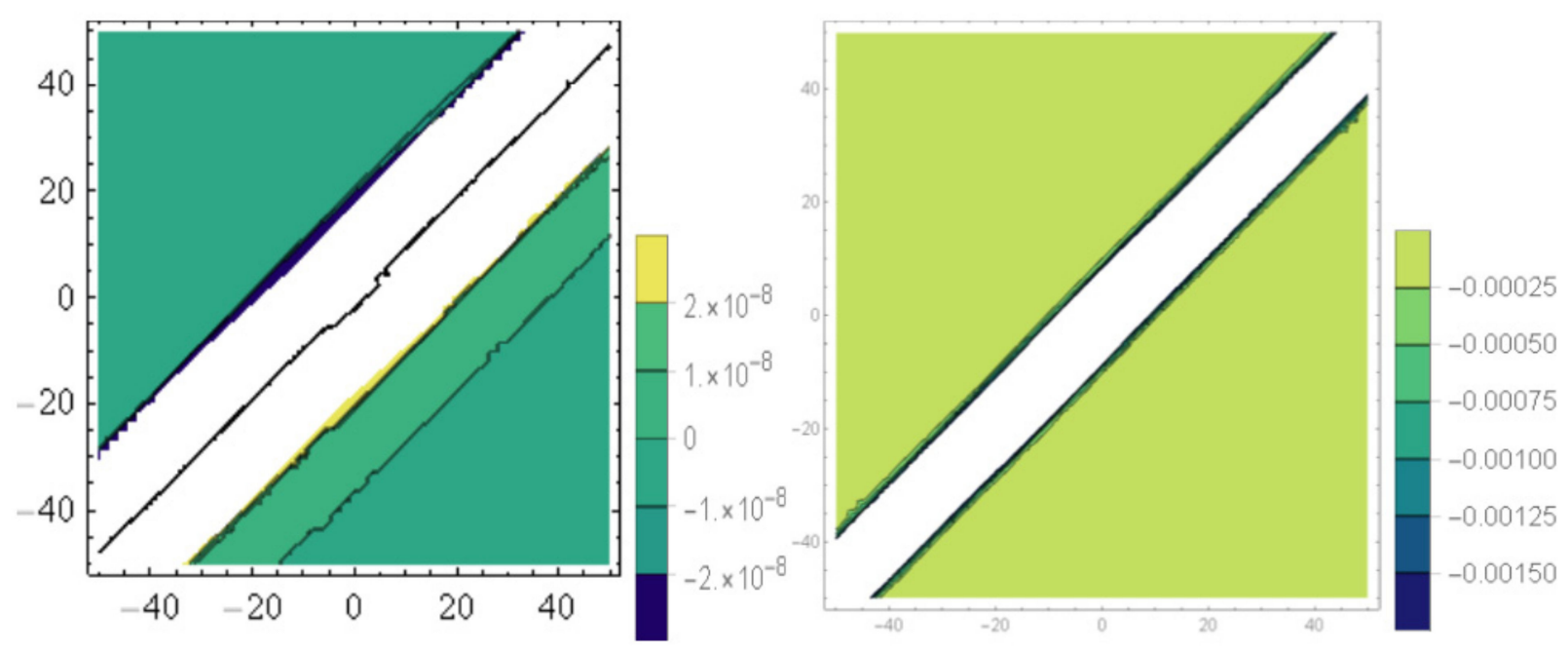

Figure 21. The contour surfaces of Equation (32) for $\varepsilon=0.4, \alpha=0.1,-50<x<50,-50<t<50$. 

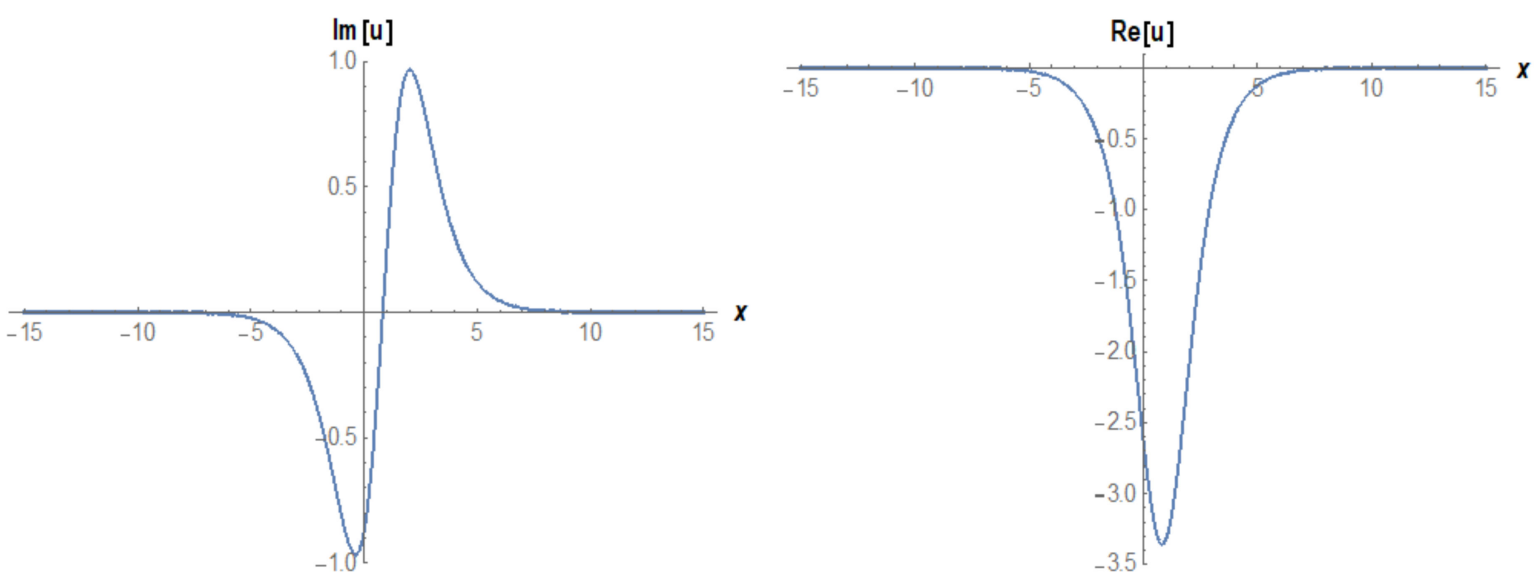

Figure 22. The 2D surfaces of Equation (32) for $\varepsilon=0.4, \alpha=0.1, t=0.5,-15<x<15$.

\section{Comparison and Discussion}

In a previous research [21], Asaduzzman et al., have studied the special cases of Equation (1) by considering $\alpha=2$. In this paper, we have extracted the general solutions of MAE according to $\alpha$ as being in the solutions of Equations (16), (18), and (32). Moreover, we have also investigated other values of $\alpha$ such as complex and rations in the coefficients of Equations (19), (21), (23), (25) and (29). When we compare these solutions with the solutions presented in the previous study [21], it may be observed that they are an entirely new solution for the governing model of MAE.

Moreover, if we consider more values of $n, M$ as $n=8$ and $M=5$, we obtain another new solution for the governing model as:

$$
U=a_{0}+a_{1} F+a_{2} F^{2}+a_{3} F^{3}+a_{4} F^{4}+a_{5} F^{5}+a_{6} F^{6}+a_{7} F^{7}+a_{8} F^{8},
$$

in which $a_{8} \neq 0, b \neq 0, d \neq 0$. By getting the necessary derivations of Equation (33) for Equation (10), we report more new complex and rational wave solutions to the MAE, which these solutions produced by BSEFM. In this regard, this projected technique is a powerful tool for obtaining new analytical solutions for the nonlinear partial differential equations.

In the physical sense, if we consider the solution of $u_{8}(x, t)$ being Equation (32), this is a complex mixed dark soliton solution for the governing model. Such reported results in this manuscript have some important properties. To illustrate this, the hyperbolic tangent (dark soliton) arises in the calculation of magnetic moment and rapidity of special relativity [50]. In this regard, it is estimated that this solution may help to better understanding of the meaning of MAE physically.

\section{Conclusions}

In this article, we have successfully applied BSEFM to the MAE. We obtained many entirely new complex and exponential characteristic properties of MAE. We observed that the results obtained with the help of the projected algorithm are new deeper investigations and a generalized version according to $\alpha$. Moreover, we have reported the strain conditions for the validity of solutions. Various wave behaviors in many simulations from Figures 1-22 have been also presented to observe wave distributions of solutions. All figures are clearly commented, which give the idea of effectiveness of the proposed schemes. The method proposed in this paper can be used to seek more travelling wave solutions of such governing models, because the method has some advantages such as easily calculations, writing programme for obtaining coefficients, and many others. 
Author Contributions: The first Author has majorly contributed to the paper. Formal analysis, H.M.B.; Writing - original draft, M.E. All authors have read and agreed to the published version of the manuscript.

Funding: This research received no external funding.

Institutional Review Board Statement: Not applicable.

Informed Consent Statement: Not applicable.

Data Availability Statement: Data available in a publicly accessible repository.

Acknowledgments: This paper belongs to the Master's thesis of the second author.

Conflicts of Interest: The authors declare no conflict of interest.

\section{References}

1. Qi, F.-H.; Huang, Y.-H.; Wang, P. Solitary-wave and new exact solutions for an extended (3+1)-dimensional Jimbo-Miwa-like equation. Appl. Math. Lett. 2020, 100, 106004. [CrossRef]

2. Cao, B. Solutions of Jimbo-Miwa Equation and Konopelchenko-Dubrovsky Equations. arXiv 2009, arXiv:0902.3308.

3. Behera, S.; Ray, S.S. An operational matrix based scheme for numerical solutions of nonlinear weakly singular partial integrodifferential equations. Appl. Math. Comput. 2020, 367, 124771. [CrossRef]

4. Syam, M.I. The solution of Cahn-Allen equation based on Bernoulli sub-equation method. Results Phys. $2019,14,102413$. [CrossRef]

5. Mendo, L. An asymptotically optimal Bernoulli factory for certain functions that can be expressed as power series. Stoch. Process. Their Appl. 2019, 129, 4366-4384. [CrossRef]

6. Rani, D.; Mishra, V. Numerical inverse Laplace transform based on Bernoulli polynomials operational matrix for solving nonlinear differential equations. Results Phys. 2020, 16, 102836. [CrossRef]

7. Lee, J.Y.; Jeon, W. Exact solution of Euler-Bernoulli equation for acoustic black holes via generalized hypergeometric differential equation. J. Sound Vib. 2019, 452, 191-204. [CrossRef]

8. Arqub, O.A.; Maayah, B. Modulation of reproducing kernel Hilbert space method for numerical solutions of Riccati and Bernoulli equations in the Atangana-Baleanu fractional sense. Chaos Solitons Fractals 2019, 125, 163-170.

9. Rahimkhani, P.; Ordokhani, Y.; Babolian, E. Numerical solution of fractional pantograph differential equations by using generalized fractional-order Bernoulli wavelet. J. Comput. Appl. Math. 2017, 309, 493-510. [CrossRef]

10. Yang, S.L. An identity of symmetry for the Bernoulli polynomials. Discret. Math. 2008, 308, 550-554.

11. Dilcher, K.; Vignat, C. General convolution identities for Bernoulli and Euler polynomials. J. Math. Anal. Appl. 2016, 435, 1478-1498.

12. Dilcher, K.; Straub, A.; Vignat, C. Identities for Bernoulli polynomials related to multiple Tornheim zeta functions. J. Math. Anal. Appl. 2019, 476, 569-584. [CrossRef]

13. Rahimkhani, P.; Ordokhani, Y.; Babolian, E. Fractional-order Bernoulli wavelets and their applications. Appl. Math. Model. 2016, 40, 8087-8107. [CrossRef]

14. Ren, Q.; Tian, H. Numerical solution of the static beam problem by Bernoulli collocation method. Appl. Math. Model. 2016, 40, 8886-8897. [CrossRef]

15. Jamei, M.M.; Beyki, M.R.; Koepf, W. An extension of the Euler-Maclaurin quadrature formula using a parametric type of Bernoulli polynomials. Bull. Des. Sci. Mathématiques 2019, 156, 102798.

16. Rahimkhani, P.; Ordokhani, Y.; Babolian, E. Fractional-order Bernoulli functions and their applications in solving fractional Fredholem-Volterra integro-differential equations. Appl. Numer. Math. 2017, 122, 66-81. [CrossRef]

17. Biswas, A.; Mirzazade, M.; Triki, H.; Zhou, Q.; Ullah, M.Z.; Moshokoa, S.P.; Belic, M. Perturbed resonant 1-soliton solution with an-ti-cubic nonlinearity by Riccati-Bernoulli sub-ODE method. Optik 2018, 156, 346-350.

18. Keshavarz, E.; Ordokhani, Y.; Razzaghi, M. The Bernoulli wavelets operational matrix of integration and its applications for the solution of linear and nonlinear problems in calculus of variations. Appl. Math. Comput. 2019, 351, 83-98. [CrossRef]

19. Zeghdane, R. Numerical solution of stochastic integral equations by using Bernoulli operational matrix. Math. Comput. Simul. 2019, 165, 238-254.

20. Marinov, T.T.; Vatsala, A.S. Inverse problem for coefficient identification in the Euler-Bernoulli equation. Comput. Math. Appl. 2008, 56, 400-410. [CrossRef]

21. Islam, N.; Asaduzzaman, M.; Ali, S. Exact wave solutions to the simplified modified Camassa-Holm equation in mathematical physics. AIMS Math. 2020, 5, 26-41. [CrossRef]

22. Wazwaz, A.M. Solitary wave solutions for modified forms of Degasperis-Procesi and Camassa-Holm equations. Phys. Lett. A 2006, 352, 500-504. [CrossRef]

23. Baskonus, H.M.; Bulut, H. On the complex structures of Kundu-Eckhaus equation via improved Bernoulli sub-equation function method. Waves Random Complex Media 2015, 25. [CrossRef] 
24. Ihan, E.; Kiymaz, I.O. A generalization of truncated M-fractional derivative and applications to fractional differential equations. Appl. Math. Nonlinear Sci. 2020, 5, 171-188.

25. Pandey, P.K.; Jaboob, S.S.A. A finite difference method for a numerical solution of elliptic boundary value problems. Appl. Math. Nonlinear Sci. 2018, 3, 311-320. [CrossRef]

26. Durur, H.; Ilhan, E.; Bulut, H. Novel Complex Wave Solutions of the (2+1)-Dimensional Hyperbolic Nonlinear Schrödinger Equation. Fractal Fract. 2020, 4, 41. [CrossRef]

27. Eskitascioglu, E.I.; Aktas, M.B.; Baskonus, H.M. New Complex and Hyperbolic Forms for Ablowitz-Kaup-Newell-Segur Wave Equation with Fourth Order. Appl. Math. Nonlinear Sci. 2019, 4, 105-112.

28. Conte, R.; Musette, M. Elliptic General Analytic Solutions. Stud. Appl. Math. 2009, 123, 63-81. [CrossRef]

29. Contel, R.; Ng, T.W. Meromorphic solutions of a third order nonlinear differential equation. J. Math. Phys. 2010, 51, 033518. [CrossRef]

30. Gao, W.; Yel, G.; Baskonus, H.M.; Cattani, C. Complex solitons in the conformable (2+1)-dimensional Ablowitz-Kaup-NewellSegur equation. AIMS Math. 2020, 5, 507-521. [CrossRef]

31. Ismael, H.F.; Bulut, H.; Baskonus, H.M.; Gao, W. Newly modified method and its application to the coupled Boussinesq equation in ocean engineering with its linear stability analysis. Commun. Theor. Phys. 2020, 72, 115002. [CrossRef]

32. Liu, J.-G.; Yang, X.-J.; Feng, Y.-Y. Analytical solutions of some integral fractional differential-difference equations. Mod. Phys. Lett. B 2020, 34, 2050009. [CrossRef]

33. Silambarasan, R.; Baskonus, H.M.; Rajasekaran, V.A.; Dinakaran, M.; Balusamy, B.; Gao, W. Longitudinal strain waves propagating in an infinitely long cylindrical rod composed of generally incompressible materials and it's Jacobi elliptic function solutions. Math. Comput. Simul. 2020, 182, 566-602. [CrossRef]

34. Ghanbari, B.; Günerhan, H.; Ilhan, O.A.; Baskonus, H.M. Some new families of exact solutions to a new extension of nonlinear Schrödinger equation. Phys. Scr. 2020, 95, 075208. [CrossRef]

35. Berna, F.B. Analysis of fractional Klein-Gordon-Zakharov equations using efficient method. Num. Method. Partial Dif. Eq. 2020. [CrossRef]

36. Houwe, A.; Sabi'U, J.; Hammouch, Z.; Doka, S.Y. Solitary pulses of a conformable nonlinear differential equation governing wave propagation in low-pass electrical transmission line. Phys. Scr. 2020, 95, 045203. [CrossRef]

37. Cordero, A.; Jaiswal, J.P.; Torregrosa, J.R. Stability analysis of fourth-order iterative method for finding multiple roots of non-linear equations. Appl. Math. Nonlinear Sci. 2019, 4, 43-56. [CrossRef]

38. Liu, J.-G.; Yang, X.-J.; Feng, Y.-Y. Characteristic of the algebraic traveling wave solutions for two extended $(2+1)$-dimensional Kadomtsev-Petviashvili equations. Mod. Phys. Lett. A 2019, 35, 2050028. [CrossRef]

39. Ozer, O. Fundamental units for real quadratic fields determined by continued fraction conditions. AIMS Math. 2020, 5, 2899-2908. [CrossRef]

40. Gao, W.; Senel, M.; Yel, G.; Baskonus, H.M.; Senel, B. New complex wave patterns to the electrical transmission line model arising in network system. AIMS Math. 2020, 5, 1881-1892. [CrossRef]

41. Yang, X.-J.; Gao, F. A new technology for solving diffusion and heat equations. Therm. Sci. 2017, 21, 133-140. [CrossRef]

42. Hosseini, K.; Samavat, M.; Mirzazadeh, M.; Ma, W.X.; Hammouch, Z. A New \$\$(3+1) \$\$-dimensional Hirota Bilinear Equation: Its Bäcklund Transformation and Rational-type Solutions. Regul. Chaotic Dyn. 2020, 25, 383-391. [CrossRef]

43. Gao, W.; Ismael, H.F.; Husien, A.M.; Bulut, H.; Baskonus, H. Optical Soliton solutions of the Nonlinear Schrödinger and Resonant Nonlinear Schrödinger Equation with Parabolic Law. Appl. Sci. 2020, 10, 219. [CrossRef]

44. Uddin, M.F.; Hafez, M.G.; Hammouch, Z.; Baleanu, D. Periodic and rogue waves for Heisenberg models of ferromag-netic spin chains with fractional beta derivative evolution and obliqueness. Waves Random Complex Media 2020. [CrossRef]

45. Cattani, C.; Sulaiman, T.A.; Baskonus, H.M.; Bulut, H. On the soliton solutions to the Nizhnik-Novikov-Veselov and the Drinfel'd-Sokolov systems. Opt. Quantum Electron. 2018, 50, 138. [CrossRef]

46. Khader, M.M.; Saad, K.M.; Hammouch, Z.; Baleanu, D. A spectral collocation method for solving fractional KdV and KdV-Burger's equations with non-singular kernel derivatives. Appl. Numer. Math. 2020. [CrossRef]

47. Yokus, A.; Sulaiman, T.A.; Baskonus, H.M.; Atmaca, S.P. On the exact and numerical solutions to a nonlinear model aris-ing in mathematical biology. ITM Web Conf. 2018, 22, 8815363. [CrossRef]

48. Sulaiman, T.A.; Yokus, A.; Gulluoglu, N.; Baskonus, H.M.; Bulut, H. Regarding the Numerical and Stability Analysis of the Sharma-Tosso-Olver Equation. ITM Web Conf. 2018, 22, 102555. [CrossRef]

49. Baskonus, H.M.; Cattani, C.; Ciancio, A. Periodic, Complex and Kink-type Solitons for the Nonlinear Model in Microtu-bules. J. Appl. Sci. 2019, 21, 34-45.

50. Weisstein, E.W. Concise Encyclopedia of Mathematics; CRC Press: New York, NY, USA, 2002. 